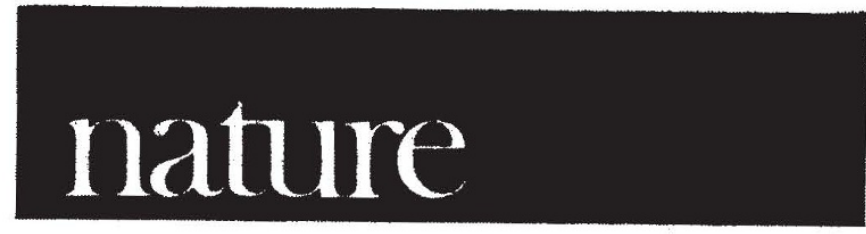

Volume 249

May 3, 1974

\section{Chips with everything}

THE science of human nutrition in Britain has fallen on hard times. Of that, even the practitioners themselves seem to agree. In the last war the nutritionist played a major and acknowledged role in keeping the public healthy (some would say healthier than ever before or since). These days scientists turn their noses up at the thought of becoming nutritionists and the public gets little or no advice on what constitutes a balanced dietapart from keeping cigarettes out of it. The situation seems to be worse, if anyting, elsewhere in Europe.

Nutrition is not an easy subject to define, as it includes so many aspects of other disciplines. Nevertheless it may be helpful to make subdivisions such as

(i) clinical nutritionists dealing with individual cases and counselling at the individual level,

(ii) scientific nutritionists working, say, on vitamins, fortification or dietary assessment techniques,

(iii) epidemiological nutritionists handling the statistics of large populations and

(iv) public nutritionists working either with government or the food industry on monitoring and information.

Who becomes a nutritionist? It is here that the problems start. There is no prescribed way into the field, but a broad biological education, probably with a medical background, is desirable. However, the job lacks kudos and the attraction of the microscopic and submicroscopic in biology draws away many talented students from study of the whole man. In medical schools, nutrition is about on a par with chiropody in appeal to students, and, for lack of good teachers, has often been introduced incidentally in other courses. A clinical nutritionist will often find himself a different title such as endocrinologist. As a result, those in nutritional departments of universities find it extraordinarily difficult to recruit high-calibre postgraduates, who regard the subject as soft and indefinite.

There is also a problem in the student's perception of a career structure. There are several senior posts in nutrition which will fall vacant in the next few years and there will be difficulty, it is said, in filling these, as there are insufficient middle level positions. Students see the lack of obvious upward steps from junior posts and they leave for better guaranteed careers.

Nutrition is very obviously a subject where the interplay between universities, industry and the public health services should be strong, but the deficiencies in career prospects in the academic sector have not been made up for by an adequacy of challenging positions elsewhere. The food industry does not employ many nutritionists (in contrast with the animal feed industry with its obvious interests in fatter beasts - the whole man may not be a proper study of mankind, but the whole pig certainly is). Those that industry does use are frequently engaged simply in ensuring the accuracy of labels or approving advertisements. Those in public service too often find themselves engaged in routine activities, whilst there are large public health educational issues which go untouched.

Obesity is a case in point. Many believe that this is the major nutritional problem facing the Western world today, not only in itself, but for the many disorders which spring from it. Yet at present next to nothing is being done by public health authorities either in prevention or cure. Nutritional counselling even of the simplest kind barely exists. And for health clubs or dieting systems claiming to reduce weight safely there is no public supervision. This at a time when the choice of foods available to the consumer is large and there is a demand for information on good eating habits.

There are, fortunately, signs of change. The recent establishment of two Royal Society Sainsbury Fellowships should go someway towards producing better prospects for career advancement. Further, there is an indication that a new generation of students has a greater interest in multi-disciplinary people-oriented biology. And the new administrative areas of the National Health Service should each have a 'community dietician'.

Much remains to be done, however, in the field of health education. The responsibility is ultimately the government's and the duty is to make the public aware of the elementary principles of sound nutrition so that more sophisticated choices can be made when buying food. It has long been a British principle to assume that intuition is a good substitute for understanding, and therefore that detailed information about the nutritional properties of food is unnecessary. It is time that such an attitude was superseded.

The results of better nutritional counselling would be unspectacular, and there would be inevitable doubts that a long-term educational programme would have any more impact than have anti-smoking campaigns. This should not deter government from taking a few inexpensive steps in the right direction. They would at least stimulate a greater commitment to nutritional studies by the food industry. In turn, this might breathe more life into research in the universities.

\section{0 years ago}

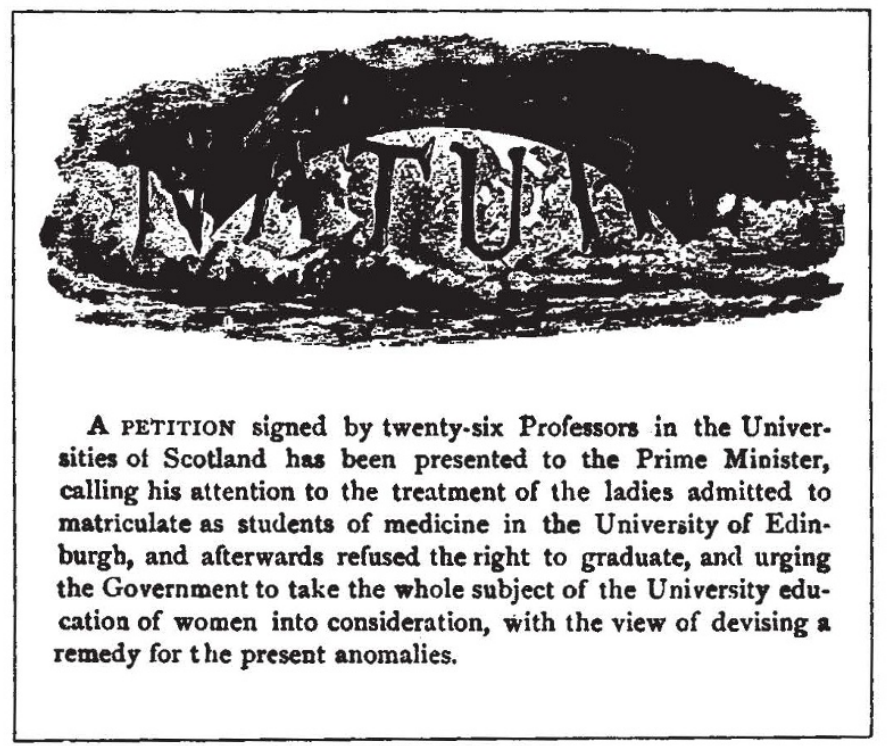

From Nature, 10, 16, May 7, 1874. 